\title{
Nurses' knowledge of pressure ulcer and its associated factors at Hawassa University comprehensive specialized hospital Hawassa, Ethiopia, 2018
}

\author{
Ezedin Molla Muhammed ${ }^{1}$, Berhanu Boru Bifftu², Yemataw Zewdu Temachu ${ }^{3}$ and Tarkie Abebe Walle 4* $^{*}$
}

\begin{abstract}
Background: Pressure ulcer is largely avoidable, but its prevalence rate increased more than $80 \%$ in a 13 years study. Nurses have a great position to advance best practices towards the prevention of pressure ulcers. Therefore they should be knowledgeable of the signs and symptoms of pressure ulcers, and preventive strategies to reduce its incidence, but there is limited evidence on nurses' knowledge and its associated factors to prevent pressure ulcers in Ethiopia.

Methods: A hospital-based cross-sectional study was conducted from March 25 - April 23/ 2018. A total of 356 nurses were selected by stratification with a simple random sampling technique. Pretested structured questionnaire with closed and open-ended questions was used to collect data. Frequency distribution and percentage were computed to describe each variable. Bivariate and multivariable logistic regression with a $95 \%$ confidence interval was also carried out to see the effect of each independent variable on the dependent variable and declared statistically significant association with $P<0.05$.

Result: The mean knowledge score of nurses was 25.22 out of 41 item questions. Fifty-two point $5 \%$ of nurses score above the mean. Males $[A O R=0.44,95 \% \mathrm{Cl}(0.26-0.73)]$, working a maximum of eight hours $[\mathrm{AOR}=3.57,95 \%$ $\mathrm{Cl}(1.48-8.61)$, not having training [(AOR $=2.31,95 \% \mathrm{Cl}(1.14-4.61)]$, Low salary $[\mathrm{AOR}=3.47,95 \% \mathrm{Cl}(1.03-11.67)]$ were significantly associated with inadequate knowledge.

Conclusion: Generally a nurse's knowledge of pressure ulcers was inadequate. Being female, working less than or equal to eight hours, not having the training and low working salary are contributors to a low level of knowledge for pressure ulcers.
\end{abstract}

Keywords: Knowledge, Nurses, Pressure ulcer prevention

\section{Background}

Pressure ulcers are described as localized injury to the skin and/or underlying tissue, usually over a bony prominence, as a result of pressure or pressure in combination with shear [1-4]. Pressure ulcers are classified in

\footnotetext{
* Correspondence: robaname@gmail.com; tarkieabebe@ymail.com ${ }^{4}$ Department of Surgical Nursing, University of Gondar, Gondar, Ethiopia Full list of author information is available at the end of the article
}

four stages by tissue layer affected ranging from skin erythema to damage to muscle and underlying bone, and which vary in size and severity of tissue damage [2].

A cross-sectional study conducted at Felegehiwot and Dessie referral hospital, in Ethiopia reported 16.8 and $14.9 \%$ overall prevalence rate of PU, respectively $[5,6]$. While caregivers practice the best care every time, patients can avoid needless suffering [7].

C C The Author(s). 2020 Open Access This article is licensed under a Creative Commons Attribution 4.0 International License, which permits use, sharing, adaptation, distribution and reproduction in any medium or format, as long as you give appropriate credit to the original author(s) and the source, provide a link to the Creative Commons licence, and indicate if changes were made. The images or other third party material in this article are included in the article's Creative Commons licence, unless indicated otherwise in a credit line to the material. If material is not included in the article's Creative Commons licence and your intended use is not permitted by statutory regulation or exceeds the permitted use, you will need to obtain permission directly from the copyright holder. To view a copy of this licence, visit http://creativecommons.org/licenses/by/4.0/. The Creative Commons Public Domain Dedication waiver (http://creativecommons.org/publicdomain/zero/1.0/) applies to the data made available in this article, unless otherwise stated in a credit line to the data. 
Pressure area care is an essential component of nursing practice, with all patients potentially at risk of developing a pressure ulcer [8].

Annually more than 2.5 million patients develop pressure ulcers in the United States of America alone [9]. Management of hospital-acquired pressure ulcers costs billions of dollars each year; for a single individual with a diagnosis of pressure ulcer costs nearly $129,000 \$$ on average [10]. A pressure ulcer is largely avoidable, but in a 13 years study, its prevalence rate increased more than $80 \%$ [11]. A comparative study conducted in Norwegian and Irish sites shows that PU prevalence was 54\% in the Norwegian and $12 \%$ in the Irish site [12]. Another study done in Sweden revealed that the 21 different countries prevalence ranged from 9 to 31\% [13]. A similar study conducted in Ethiopia indicates that off total among total admitted patients $16.8 \%$ of them had a pressure ulcer [5].

Hospitals need to devote more resources to prevent and manage pressure ulcers. Professionals should also meet their responsibility to provide continuous nursing and medical education to staff about pressure ulcers [14].

Adequate application of incontinence management and measures are taken to prevent skin damage, such as preventive skincare based on principles of cleansing, enhancing the skin's moisture barrier, and regular turning and repositioning along with protection [15]. Timely and accurate assessment of pressure ulcers depends on individual need, with education on skin and risk assessment forming a key component [16].

Nurses have a great position to advance best practices towards the prevention of PU. Therefore they are in need to be knowledgeable about the signs and symptoms of pressure ulcers, and preventive strategies to reduce its incidence [16]. But according to a study conducted across the globe nurses do not have sufficient knowledge about pressure ulcer prevention, classification, and management [17]. Studies in Nepal revealed that only 59\% of nurses had adequate knowledge about pressure ulcer prevention [18]. A similar study conducted in North West Ethiopia shows nearly half $54.4 \%$ of the nurses had good knowledge of pressure ulcer prevention [19].

The prevalence of pressure ulcers decreased if the patient is assessed for the risk of pressure ulcer upon his/ her admission and if a regular assessment is followed by appropriate action or intervention [20]. Providing sufficient education, a positive attitude, and addressing barriers are all important aspects to improve the knowledge and use of pressure ulcer preventive measures among nursing staff [21]. Understands nurses' knowledge about pressure ulcer prevention, classification, and management is important to improve their knowledge of pressure ulcer prevention.

\section{Justification of the study}

$\mathrm{PU}$ is a major significant and complex problem in hospitals in terms of human suffering, tissue necrosis, pain, septicemia, disfigurement, loss of productivity, and financial burden. Nurses have typically expended most of their time with the patients. Therefore nurses have a pivotal position and role to prevent and manage pressure ulcers by correcting interdisciplinary teamwork. So nurses require complete knowledge to prevent and monitor all conditions associated with pressure ulcer occurrences.

To my best search, there is limited evidence on nurses' knowledge and its associated factors towards pressure ulcer prevention in Ethiopia as general, and there has been no published data particularly in the study area. Therefore, information emanating from this study will be a valuable reason for the future in developing appropriate educational strategies and training in this area.

\section{Objectives \\ General objective}

To assess Nurses' knowledge towards pressure ulcer prevention, and its associated factors in Hawassa University Comprehensive Specialized Hospital, Hawassa, Ethiopia, 2018.

\section{Specific objectives}

- To determine knowledge of nurses' on pressure ulcer prevention at Hawassa University Comprehensive Specialized Hospital, Hawassa, Ethiopia, 2018.

- To identify factors associated with the knowledge of nurses on pressure ulcer prevention at Hawassa University Comprehensive Specialized Hospital, Hawassa, Ethiopia, 2018.

\section{Methods \\ Study design, area and period}

The institution-based cross-sectional study design was conducted from March 25 - April 23/ 2018. The study was conducted in Hawassa University comprehensive specialized Hospital, Hawassa. Hawassa is found in southern Ethiopia, on the shores of Lake Hawassa in the great rift valley; $273 \mathrm{~km}$ South of Addis Ababa via Debre Zeit and $1125 \mathrm{~km}$ North of Nairobi. Currently, Hawassa town has one comprehensive specialized hospital, one regional hospital, and eight government health centers. Hawassa University Comprehensive Specialized Hospital is a teaching Hospital that gives services for more than five million people including Sidama zone and peoples of the neighboring zones and regions. In this teaching hospital, there are multidisciplinary professionals with different specialties are found, among them the big 
number is taken by nurses, nearly five hundred nurses currently serving in different units and office in the hospital.

\section{Source and study population}

The source population was all nurses working at Hawassa university comprehensive specialized hospital. The study subjects were those nurses working at Hawassa University Comprehensive Specialized Hospital during the data collection period.

\section{Inclusion and exclusion criteria}

All permanent staff nurses working at Hawassa University Comprehensive Specialized Hospital who were available during the study period were included in the study.

\section{Sample size determination and sampling procedure Sample size}

The sample size determined by using a single population proportion formula and considering the following assumptions: nurses knowledge on pressure ulcer prevention 36.15 [21]. = standard normal distribution value at 95\% confidence level of $Z \alpha / 2=1.96$ and margin of error (d) $=5 \%$.

$$
\mathrm{n}=\frac{(\mathrm{Z} \alpha / 2)^{2} \mathrm{P}(1-\mathrm{P})}{\mathrm{d}^{2}}[22]
$$

The final sample size was determined considering a $10 \%$ non-response rate, the total sample size was 391 nurses.

\section{Sampling procedures}

Stratification with a Simple random sampling method was used to select the study subjects after proportional allocation for each working ward/unit. The study participants were selected from each ward/unit by a simple random sampling technique from the list of nurses in each stratum (Fig. 1).

\section{Operational definitions}

- Good knowledge: Nurses, who scored above the mean score of the knowledge questions towards pressure ulcer

- Poor knowledge: Nurses, who scored mean and above the mean of the knowledge questions towards pressure ulcer [19].

\section{Data collection tools and procedures}

Self-administer structured questionnaire containing both closed and open-ended questions were used to collect data. The data was collected from March 25 - April 23/ 2018. The question focused on Nurse's knowledge, perceived barrier, work-related factors, and socio-demographic characteristics towards pressure ulcer prevention. Knowledge of nurses was assessed by 41 true/false questions and by using Pieper-Zulkowski Pressure Ulcer knowledge test (PZPUKT) [23], in its version adapted and validated to Brazil [24]. Perceived barrier questions that include un Proportionate nurse to patient ratio, Lack of guidelines, Shortage of time, Limited resource, Patient factors, Lack of evidence supported by research, Lack of training, lack of job satisfaction, Lack of knowledge were assessed by using a 5 item Likert scale (ranging from strongly agreed, 5 to strongly disagree, 1) adapted from different published literature [14, $19,25,26]$.

\section{Data quality control, processing, and analysis}

To keep the quality of the collected data all possible attempts were made starting from the development of a data collection instrument to completeness checking of the filled questionnaires. The questionnaire was pretested on 20 (5\%) nurses who were working at Gondar University Comprehensive Specialized Hospital, 1 week before the initiation of the main study. And necessary corrections were made and the questions were simplified based on the pretest findings. To ensure the quality of data collection, orientation training about the data collection process was given for data collectors.

EPI-INFO version 7 statistical software was used for data entry. Then it was exported to SPSS version 20.0 for analysis. Frequency distribution and the percentage were computed to describe each variable. Binary logistic regression analysis was employed to determine the association of independent variables with the nurse's knowledge of pressure ulcer prevention. Odds ratio with $95 \%$ confidence interval was calculated, the variables that are found with $P<0.2$ at bivariate analysis were entered to multivariable analysis and statistical significance was declared at $p$-value less than 0.05 . Finally, results were presented using tables and figures.

\section{Results}

Socio-demographic characteristics of respondents

Overall, among 532 nurses who were working regularly at Hawassa University Comprehensive Specialized Hospital 391 nurses were selected for the study and 356 (91.05\%) responded to the question, 35 nurses refused to respond the self-administered questionnaire. Of all 185 (52\%) were females. The mean age of the study subjects was 27.39 years, $80.30 \%$ were aged less than 30 years and above 39 years. The Amhara ethnic group comprised $28.7 \%$ of the study subjects followed by Oromo (14\%). Nearly half of the study subjects were orthodox by religion $(46.30 \%)$, followed by protestant (Table 1 ).

\section{Work-related characteristics}

Among all nurses involved in the study (74.70\%) have a bachelor's degree and the rest (25.30\%) were diploma 


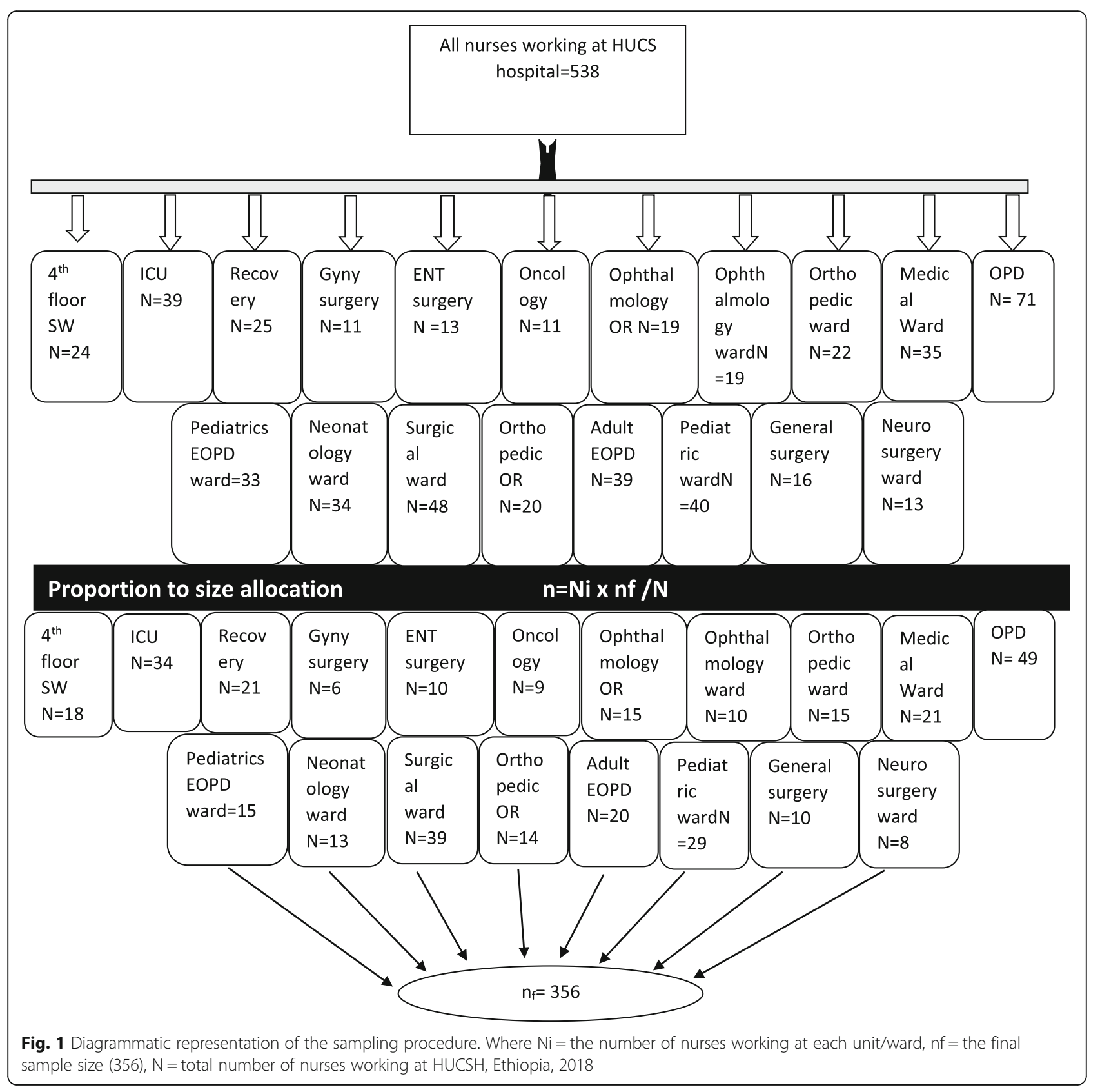

holders. Forty-seven percent of the study subjects were having an experience of fewer than 5 years, $(45.8 \%)$ reported they have $5-10$ years and the rest $(7 \%)$ were had more than 10 years of experience. Of the total nurse, $41.90 \%$ were working at the inpatient department, followed by (19.1\%) intensive care unit. Experience of less than 1 year in the current ward/department accounts $(53.9 \%)$, followed by $1-2$ years $(26.7 \%)$, and $>2$ years (19.4\%). Among nurses, only 33\% were got less than 3201 birrs monthly salary. Towards working position $3.9 \%$ were ward head, $7.9 \%$ team leader, $6.7 \%$ focal person, and $81.5 \%$ nurses who care only the patient with no additional leadership/ward head role (Table 1).

\section{Nurses knowledge of pressure ulcer prevention}

Among 356 nurse Participants 52.5\% were scored above the mean and the rest $47.5 \%$ were scored mean and below the mean out of 41 item questions. The nurses answered correctly $57.9 \%( \pm 1.44)$ of the question in the pressure ulcer classification and evaluation section. The highest rate of the correct answer was 86\% (Stage IV pressure ulcers present total tissue loss, with intensive destruction and necrosis of the tissue or damage to the muscles, bones, or supporting structures) and also with 75.6\% (Stage I pressure ulcers are defined as intact skin with hyperemia of a localized area and non-bleachable redness or different color from the surrounding area). 
Table 1 Socio-demographic characteristics of nurses towards pressure ulcer prevention at Hawassa University Comprehensive Specialized Hospital, 2018

\begin{tabular}{|c|c|c|}
\hline Characteristics $(\boldsymbol{n}=356)$ & Frequency & Percent \\
\hline Sex & 356 & 100.00 \\
\hline Male & 171 & 48.00 \\
\hline Female & 185 & 52.00 \\
\hline \multicolumn{3}{|l|}{ Age } \\
\hline $20-29$ & 286 & 80.30 \\
\hline $30-39$ & 61 & 17.10 \\
\hline$>39$ & 9 & 2.50 \\
\hline \multicolumn{3}{|l|}{ Ethnicity } \\
\hline Sidama & 46 & 12.90 \\
\hline Amhara & 102 & 28.70 \\
\hline Wolaita & 39 & 11.00 \\
\hline Oromo & 50 & 14.00 \\
\hline Tigrie & 21 & 5.90 \\
\hline Gurage & 40 & 11.2 \\
\hline Others & 58 & 16.3 \\
\hline \multicolumn{3}{|l|}{ Religion } \\
\hline Protestant & 162 & 45.50 \\
\hline Orthodox & 165 & 46.30 \\
\hline Muslim & 16 & 4.50 \\
\hline Catholic & 5 & 1.40 \\
\hline Other & 8 & 2.20 \\
\hline \multicolumn{3}{|l|}{ Marital status } \\
\hline Single & 190 & 53.40 \\
\hline Married & 163 & 45.80 \\
\hline Divorced & 2 & 0.60 \\
\hline Widowed & 1 & 0.30 \\
\hline \multicolumn{3}{|l|}{ Level of Qualification } \\
\hline Diploma & 90 & 25.30 \\
\hline Bachelor degree & 266 & 74.70 \\
\hline \multicolumn{3}{|l|}{ Total work experience } \\
\hline $0-4$ years & 168 & 47.20 \\
\hline $5-10$ years & 163 & 45.80 \\
\hline$>10$ years & 25 & 7.00 \\
\hline \multicolumn{3}{|l|}{ Working ward currently } \\
\hline Intensive care unit & 68 & 19.10 \\
\hline Inpatient ward & 149 & 41.90 \\
\hline Operation room & 55 & 15.40 \\
\hline Emergency department & 35 & 9.80 \\
\hline Outpatient department & 49 & 13.80 \\
\hline Variable & Frequency & Percent \\
\hline \multicolumn{3}{|l|}{ Monthly income } \\
\hline$<103.2$ USD & 33 & 9.30 \\
\hline
\end{tabular}

Table 1 Socio-demographic characteristics of nurses towards pressure ulcer prevention at Hawassa University Comprehensive Specialized Hospital, 2018 (Continued)

\begin{tabular}{|c|c|c|}
\hline Characteristics $(\boldsymbol{n}=356)$ & Frequency & Percent \\
\hline $103.2-169.3$ USD & 177 & 49.70 \\
\hline 169.4-251.6 USD & 116 & 32.60 \\
\hline$>251.6$ USD & 30 & 8.40 \\
\hline \multicolumn{3}{|l|}{ Working position } \\
\hline Ward head & 14 & 3.90 \\
\hline Team leader & 28 & 7.90 \\
\hline Focal person & 24 & 6.70 \\
\hline No position/ Technical staff & 290 & 81.50 \\
\hline \multicolumn{3}{|c|}{ Additional work other than this hospital } \\
\hline Yes & 195 & 54.80 \\
\hline No & 161 & 45.20 \\
\hline \multicolumn{3}{|c|}{ Average daily duration of working time in the hospital } \\
\hline$\leq 8 \mathrm{~h}$ & 169 & 47.50 \\
\hline $9-12 \mathrm{~h}$ & 127 & 35.70 \\
\hline$>12 \mathrm{~h}$ & 60 & 16.90 \\
\hline \multicolumn{3}{|c|}{ Did you receive training about PU } \\
\hline Never received training & 300 & 84.30 \\
\hline Lecture & 38 & 10.70 \\
\hline Course & 13 & 3.70 \\
\hline Conference & 2 & 0.60 \\
\hline Workshop & 3 & 0.80 \\
\hline \multicolumn{3}{|c|}{ How often read literature about PU } \\
\hline Never & 137 & 38.5 \\
\hline Always & 22 & 6.2 \\
\hline Sometimes & 197 & 55.3 \\
\hline
\end{tabular}

The lowest rate was $16.9 \%$ (Stage II pressure ulcers present loss of dermis in its total thickness).

\section{Factors associated with nurse's knowledge towards pressure ulcer}

Regarding this, sex (AOR 0.56, 95\% CI 0.36-0.88), working hour (AOR 2.57, 95\% CI 1.17-5.61), salary (AOR 3.47, 95\% CI 1.03-11.67), and training. (AOR 2.31, 95\% CI 1.14-4.61) were shown to have a strong statistical association during multivariable analysis (Table 2).

\section{Discussion}

The finding of this study shows that nurses who scored above the average score were $52.5 \%$. The proportion of nurses who scored above the average value in the current study was lower than the studies conducted in Sweden (58.9\%), Brazil (63.4\%), and Addis Ababa Ethiopia $63.85 \%[22,23,26]$. The difference might be due to the variation in the socio-economic and health care system of the countries. 
Table 2 Factors associated with Nurses knowledge towards pressure ulcer prevention at Hawassa University Comprehensive Specialized Hospital, 2018

\begin{tabular}{|c|c|c|c|c|}
\hline \multirow[t]{3}{*}{ Variables } & \multicolumn{2}{|c|}{ Nurses total knowledge score } & \multirow[t]{3}{*}{$\operatorname{COR}(95 \% \mathrm{Cl})$} & \multirow[t]{3}{*}{$\mathrm{AOR}(95 \% \mathrm{Cl})$} \\
\hline & $>25$ & $0-25$ & & \\
\hline & No $(\%)$ & No $(\%)$ & & \\
\hline \multicolumn{5}{|l|}{ sex } \\
\hline male & $102(59.60)$ & $69(40.40)$ & $0.57(0.37-0.87)^{\mathrm{a}}$ & $0.563(0.36-0.88)^{\mathrm{a}}$ \\
\hline female & $85(45.90)$ & $100(54.10)$ & 1.00 & 1.00 \\
\hline \multicolumn{5}{|l|}{ salary } \\
\hline$<3201$ & $13(39.40)$ & $20(60.60)$ & $6.15(1.97-19.14)^{\mathrm{a}}$ & $3.47(1.03-11.67)^{\mathrm{a}}$ \\
\hline $3201-5250$ & $84(47.50)$ & $93(52.50)$ & $4.43(1.72-11.36)^{\mathrm{a}}$ & $3.90(1.42-10.68)^{\mathrm{a}}$ \\
\hline $5201-7800$ & $66(56.90)$ & $50(43.10)$ & $3.03(1.15-7.97)^{\mathrm{a}}$ & $2.95(1.04-8.30)^{\mathrm{a}}$ \\
\hline$>7800$ & $24(80)$ & $6(20.00)$ & 1.00 & 1.00 \\
\hline \multicolumn{5}{|c|}{ Additional timework other than this hospital } \\
\hline yes & $117(60.00)$ & $78(40.00)$ & $0.51(0.33-0.78)^{a}$ & $1.88(0.78-4.51)$ \\
\hline no & $70(43.50)$ & $91(56.50)$ & 1.00 & 1.00 \\
\hline \multicolumn{5}{|l|}{ Average working time } \\
\hline$\leq 8 \mathrm{~h}$ & $71(42.00)$ & $98(58.00)$ & $2.25(1.47-3.45)^{\mathrm{a}}$ & $2.57(1.17-8.301)^{a}$ \\
\hline$>8 \mathrm{~h}$ & $116(62.00)$ & $71(38.00)$ & 1.00 & 1.00 \\
\hline \multicolumn{5}{|l|}{ Receive training } \\
\hline Never & $150(50.00)$ & $150(50.00)$ & $1.94(1.07-3.54)^{\mathrm{a}}$ & $2.31(1.14-4.61)^{\mathrm{a}}$ \\
\hline Have training & $37(66.10)$ & $19(33.90)$ & 1.00 & 1.00 \\
\hline \multicolumn{5}{|l|}{ Read literatures } \\
\hline Never & $61(44.50)$ & $76(55.50)$ & $1.688(1.09-2.59)^{\mathrm{a}}$ & $1.47(0.88-2.45)$ \\
\hline Read sometimes and often & $126(57.60)$ & $93(42.50)$ & 1.00 & 1.00 \\
\hline
\end{tabular}

Key: ${ }^{\text {a }}$ significant variables

In this study nurses correctly answered $57.9 \%$ of the eight-question items on the pressure ulcer classification and evaluation section. This finding is congruent with a study done in Iran which is $57 \%$ of all questions correctly answered by the respondents [27].

In the section of pressure ulcer prevention, a 33 item questionnaire was used, the current study result revealed that $62.4 \%$ question correctly answered by nurse respondents. This is in line with a study conducted in Iran and other countries with the result score $64.8 \%$ of pressure ulcer prevention questions answered correctly [17, 23, 28].

Knowledge of pressure ulcer prevention was also found to have a significant difference among gender groups. The proportion of subjects with poor knowledge was $44 \%$ lower among males than female nurses (AOR 0.56, 95\% CI 0.36-0.88). This higher proportion of female nurses with a low level of knowledge might be related to the presence of additional responsibilities that females have in our society as it can limit the time they probably require to improve their professional knowledge. Furthermore, it could also limit their level of exposure which has been identified as a significant contributor for knowledge of nurses on pressure ulcer prevention. And this finding supported by previous studies conducted in different countries [29-31].

The present study revealed that nurses whose working time less than or equal to eight hours were 2.57 times much likely to have poor knowledge towards pressure ulcer prevention compared to nurses whose working time were more than eight hours (AOR 2.57, 95\% CI 1.17-5.61). This could be since spending much time in the working environment will increase professional exposures for different activities in a hospital setup. As a result, their awareness level could be higher when compared to those who have a limited level of exposure for such types of medical cases. Besides, these repeated exposures may also give a chance to explore causes and possible prevention measures $(10,1530)$.

According to the findings of this study nurses who had no training on pressure ulcer prevention were 2.08 times high likely to have poor knowledge about pressure ulcer prevention compared to nurses who had training. (AOR 2.31, 95\% CI 1.14-4.61) This result is in line with a study done in North West Ethiopia [19, 32].

In the current study statistically significant association was found among nurses who have a salary of fewer than 
3201 birds were 3.4 times or (AOR 3.47, 95\% CI 1.0311.67), 3201-5250 birr was 3.9 times or (AOR 3.90, 95\% CI 1.42-10.68) and those who got 5201-7800 birr were 2.9 times (AOR 2.94, 95\% CI 1.04-8.30) high likely to have inadequate knowledge towards pressure ulcer compared to nurses with payment of more than 7800 birrs. This might be due to those nurses who got minimum salary may spend their free time working in another health facility to maximize their income this may lead to lack of time to read literature about pressure ulcer prevention and also it may be moral distress among nurses towards their salary could lead to not having good interest to know more about pressure ulcer prevention [14, 24, 33].

\section{Strengths and limitations}

The strength of this study is using standard tools and this enhances the validity of the result and conclusion.

We use true/false questions in addition to PieperZulkowski Pressure Ulcer knowledge test (PZ-PUKT) and we used mean score to define the level of knowledge. It might consider as a limitation because true/false questions are not in the form of a Likert scale and will affect the conclusion due to poor scoring of the mean. Likert scale is more recommended than true/false questions to calculate the mean.

\section{Conclusion}

This study demonstrates that the Knowledge of nurses on pressure ulcer prevention is poor. The proportion of poor knowledge is higher among females, those who have low working hours and not having training were factors associated with a low level of knowledge, and low salary among nurses has a contribution of poor knowledge among nurses.

\section{Recommendation}

Measures to improve nurse's knowledge in pressure ulcer prevention needs to be conducted by giving priority for female nurses, those who have low working hours, and not having training on pressure ulcer prevention. Incorporating in the nursing curriculum, and formulating guidelines and improving the salary of nurses are some of the primary points to enhance nurses' knowledge about pressure ulcer prevention. Furthermore, we recommend a multi-centered study to identify additional factors and effective interventions for addressing pressure ulcer prevention.

\section{Abbreviations}

AOR: Adjusted Odds Ratio; COR: Crude Odds Ratio; ENT: Ear Nose Throat; EPUAP: European Pressure Ulcer Advisory Panel; HAPU: Hospital-Acquired Pressure Ulcer; HUCSH: Hawassa University Comprehensive Specialized Hospital; ICU: Intensive Care Unit; NICU: Neonatal Intensive Care Unit; NPUAP: National Pressure Ulcer Advisory Panel; OPD: Out Patient Department; PU: Pressure Ulcer; PZ-PUKT: Pieper-Zulkowski Pressure Ulcer
Knowledge Test; SNNPR: Southern Nations Nationalities and Peoples Region; SPSS: Statistical Package for Social Sciences

\section{Acknowledgments}

We would like to thank Hawassa and Gondar University Comprehensive Specialized Hospital and all the study participants who voluntarily participated in this study.

\section{Authors' contributions}

EM carried out the study starting from conception, analysis, and interpretation of data and reviewing the manuscript. BB participated in proposal writing, data analysis, interpretation, and critical review of the manuscript. YZ and TA participated in reviewing, data analysis, drafting, and commenting on the manuscript. All authors read and approved the final draft of the manuscript.

\section{Authors' information}

1. Lecturer in the school of nursing, College of Medicine and Health Sciences at of Hawassa University, Ethiopia. He has a Bachelor of Science Degree in Nursing, and MSc in Surgical Nursing Specialization.

2. Lecturer at the school of nursing, College of Medicine and Health Sciences at the University of Gondar, Ethiopia. He has a Bachelor of Science Degree in Nursing, and MSc in Psychiatry Specialization

3. Lecturer at the school of nursing, College of Medicine and Health Sciences at the University of Gondar, Ethiopia. He has a Bachelor of Science Degree in Nursing, and MSc in emergency medicine and critical care nursing Specialization

4. Assistant professor in the school of nursing, College of Medicine and Health Sciences at the University of Gondar, Ethiopia. He has a Bachelor of Science Degree in Nursing, and MSc in Surgical Nursing Specialization.

Funding

No funder.

\section{Availability of data and materials}

The datasets used and/or analyzed during the current study available from the corresponding author on reasonable request.

\section{Ethics approval and consent to participate}

Ethical clearance was obtained from the University of Gondar College of medicine and health science school of nursing, Ethical Review Committee. An Official letter was written from Hawassa University Comprehensive Specialized Hospital. Then permission and support letter was written to each respected departments and wards. The purpose of the study was explained to the study subjects and written consent was taken from the participants to confirm whether they are willing to participate. Confidentiality of responses was also ensured throughout the research process.

Consent for publication

Not applicable.

\section{Competing interests}

The authors declare that they have no competing interests.

\section{Author details}

${ }^{1}$ Hawassa University Comprehensive Specialized Hospital, Hawssa, Ethiopia. ${ }^{2}$ Department of Psychiatry Nursing, University of Gondar, Gondar, Ethiopia. ${ }^{3}$ Department of Emergency Nursing, University of Gondar, Gondar, Ethiopia. ${ }^{4}$ Department of Surgical Nursing, University of Gondar, Gondar, Ethiopia.

Received: 8 August 2019 Accepted: 8 June 2020

Published online: 15 June 2020

\section{References}

1. National Pressure Ulcer Advisory Panel, European Pressure Ulcer Advisory Panel and, Alliance PPPI. Prevention and Treatment of Pressure Ulcers: Quick Reference Guide. Cambridge Media. 2014

2. National, Institute, for, health, and, care. Pressure ulcers: prevention and management. NICE. 2014.

3. Woo KY, Sears K, Almost J, Wilson R, Whitehead M, VanDenKerkhof EG Exploration of pressure ulcer and related skin problems across the spectrum 
of health care settings in Ontario using administrative data. Int Wound J. 2017;14(1):24-30.

4. Dugaret E, Videau MN, Faure I, Gabinski C, Bourdel-Marchasson I, Salles N. Prevalence and incidence rates of pressure ulcers in an emergency department. Int Wound J. 2014;11(4):386-91.

5. Gedamu H, Hailu M, Amano A. Prevalence and associated factors of pressure ulcer among hospitalized patients at Felegehiwot referral hospital, Bahir Dar. Ethiopia. Adv Nurs. 2014;2014:8.

6. Bereded DT, Salih MH, Abebe AE. Prevalence and risk factors of pressure ulcer in hospitalized adult patients; a single center study from Ethiopia. BMC Res Notes. 2018;11:1-6. https://doi.org/10.1186/s13104-018-3948-7.

7. Institute for Healthcare Improvement (IHI). $|H|$ improvement map:prevention of pressure ulcers. IHI: 2012.

8. National Institute for Health and Care Excellence. Pressure ulcers: prevention and management. Clinical guideline 179. London: NICE; 2014.

9. CH. L. The benefits of a multi-disciplinary approach to the prevention and treatment of pressure ulcers. Infection Control Today August 2011.

10. Tallier PC, Reineke PR, Asadoorian K, Choonoo JG, Campo M, MalmgreenWallen C. Perioperative registered nurses knowledge, attitudes, behaviors, and barriers regarding pressure ulcer prevention in perioperative patients. Appl Nurs Res. 2017;36:106-10.

11. Lyder CHAE. Annual checkup: the CMS pressure ulcer present on admission indicator. Adv Skin Wound Care. 2009;22(10):476-84.

12. Moore Z, Johansen E, van Etten M, Strapp H, Solbakken T, Smith BE, et al. Pressure ulcer prevalence and prevention practices: a cross-sectional comparative survey in Norway and Ireland. J Wound Care. 2015;24(8):333-9.

13. Gunningberg L, Hommel A, Bååth C, Idvall E. The first national pressure ulcer prevalence survey in the county council and municipality settings in Sweden. J Eval Clin Pract. 2013;19(5):862-7.

14. Mwebaza I, Katende G, Groves S, Nankumbi J. Nurses' knowledge, practices, and barriers in care of patients with pressure ulcers in a Ugandan teaching hospital. Nurs Res Pract. 2014;2014:8.

15. Lachenbruch C, Ribble D, Emmons K, VanGilder C. Pressure ulcer risk in the incontinent patient: analysis of incontinence and hospital-acquired pressure ulcers from the international pressure ulcer prevalence ${ }^{T M}$ survey. J Wound Ostomy Continence Nurs. 2016;43(3):235-41.

16. Joseph J, Clifton SD. Nurses' knowledge of pressure ulcer risk assessment. Nurs Stand. 2013;27(33):54-60.

17. Rafiei H, Abdar ME, Iranmanesh S, Lalegani $H$, Safdari A, Dehkordi AH. Knowledge about pressure ulcer prevention, classification, and management: a survey of registered nurses working with trauma patients in the emergency department. Int J Orthop Trauma Nurs. 2014;18(3):135-42.

18. Shrestha N, Shrestha P. Knowledge of pressure ulcer management among nurses. J Gandaki Med Coll Nepal. 2017;9(2):47-51.

19. Nuru N, Zewdu F, Amsalu S, Mehretie Y. Knowledge and practice of nurses towards prevention of pressure ulcer and associated factors in Gondar University Hospital, Northwest Ethiopia. BMC Nurs. 2015;14:34.

20. Shahin ES, Dassen T, Halfens RJ. Pressure ulcer prevalence and incidence in intensive care patients: a literature review. Nurs Crit Care. 2008;13(2):71-9.

21. Meesterberends E, Wilborn D, Lohrmann C, Schols JM, Halfens RJ. Knowledge and use of pressure ulcer preventive measures in nursing homes: a comparison of Dutch and German nursing staff. J Clin Nurs. 2014; 23(13-14):1948-58.

22. Wiley, D. Biostatistics: A Foundationfor Analysis in the Health Sciences (7th edition.). New York: Wiley 1999

23. Chianca TC e, RJF P. Pressure ulcer knowledge among nurses in a Brazilian university hospital. Ostomy/Wound Management; 2010. p. 56.

24. Galvao NS, Serique MA, Santos VL, Nogueira PC. Knowledge of the nursing team on pressure ulcer prevention. Revista Brasileira de enfermagem. 2017; 70(2):294-300.

25. Saleh MY, Al-Hussami M, Anthony D. Pressure ulcer prevention and treatment knowledge of Jordanian nurses. J Tissue Viability. 2013;22(1):1-11.

26. Dilie A, Mengistu D. Assessment of nurses' knowledge, attitude, and perceived barriers to expressed pressure ulcer prevention practice in Addis Ababa government hospitals, Addis Ababa, Ethiopia, 2015. Adv Nurs. 2015; 2015.

27. Fernandes LM, MHL C. Uso da escala de Braden e de Glasgow para identificação do risco para úlceras de pressão em pacientes internados em centro de terapia intensiva. Rev Latino-Am Enfermagem. 2008;16(6):973-8.

28. Rafiei $H$, Mehralian $H$, Abdar ME, Madadkar T. Pressure ulcers: how much do nursing students really know? Br J Nurs. 2015;24(Sup6):S12-S7.
29. Gunningberg L, Mårtensson G, Mamhidir AG, Florin J, Muntlin Athlin Å, Bååth C. Pressure ulcer knowledge of registered nurses, assistant nurses and student nurses: a descriptive, comparative multicentre study in Sweden. Int Wound J. 2015;12(4):462-8.

30. Etafa W, Argaw Z, Melese B. Nurses' knowledge and perceived barriers about pressure ulcer prevention for admitted patients in public hospitals in Addis Ababa, Ethiopia. Am J Int Med. 2017;18(6):1203-11.

31. Sullivan N, Schoelles KM. Preventing In-Facility Pressure Ulcers as a Patient Safety StrategyA Systematic Review. Ann Intern Med. 2013;158(5_Part_2): 410-6.

32. Miyazaki MY, Caliri MHL, CBd S. Knowledge of pressure ulcer prevention among nursing professionals. Rev Latino-Am Enfermagem. 2010;18:6.

33. Shidi ASA. Pressure ulcer management in Oman: nurses' knowledge and views. RCN 2015 research conference April 20-22, Nottingham, UK (Appendix 6); 2016.

\section{Publisher's Note}

Springer Nature remains neutral with regard to jurisdictional claims in published maps and institutional affiliations.

\section{Ready to submit your research? Choose BMC and benefit from:}

- fast, convenient online submission

- thorough peer review by experienced researchers in your field

- rapid publication on acceptance

- support for research data, including large and complex data types

- gold Open Access which fosters wider collaboration and increased citations

- maximum visibility for your research: over $100 \mathrm{M}$ website views per year

At BMC, research is always in progress.

Learn more biomedcentral.com/submissions 